\title{
La jerarquía de la mesa y el diseño de la vajilla como elementos de educación artística desde la cultura visual
}

RICARD HUERTA

\section{Resumen}

El presente artículo analiza aspectos novedosos en relación los territorios del diseño, la cerámica y la docencia en educación artística. Revisamos el concepto de la vajilla y abordamos las jerarquías de la mesa, lo cual que nos lleva a intercalar cuestiones históricas, estéticas y educativas, recorriendo la tradición que emparenta los usos de la comida y el diseño entre la edad media y la época actual. Reivindicamos el papel del artesano, como concepto que emparenta la producción de objetos con el trabajo docente, desde la mirada pragmatista de Richard Sennett.

Palabras clave:

Arte, educación, cerámica, vajilla, cultura visual 


\title{
The hierarchy of the table and the crockery's design as elements for art education from visual culture
}

\author{
RICARD HUERTA
}

\begin{abstract}
In this paper we analyze new aspects of the territories of design, ceramics and teaching in art education. We review the concept of the crockery elements and boarded the table hierarchies, combining historical, aesthetic and educational issues, covering the tradition which relates the uses of food and design between the Medieval Era and modern times. We claim the role of the artisan-craftsman as a concept which relates the production of objects with school work from perception of pragmatist sociologist Richard Sennett.
\end{abstract} Art, education, ceramics, crockery, visual culture 


\section{Proyecto}

Este artículo forma parte de las investigaciones del proyecto de I+D+i Observatoriode Educación Patrimonial en España (OEPE) en su plazo anterior (2010-2012) con referencia EDU2009-09679 y en su continuación actual (2013-2015) "Educación Patrimonial en España: Consolidación, evaluación de programas e internacionalización del Observatorio de Educación Patrimonial en España (OEPE)" con referencia EDU2012-37212.

\section{Introducción}

El presente trabajo parte de una solicitud de la Escola d'Art $i$ Superior de Ceràmica de Manises cuyos responsables me invitaron a participar en las jornadas Senses 2014 Artesanía High Tech para mesa. Se agradece el acierto de haber planteado estas jornadas desde un posicionamiento multidisciplinar, ya que permite contrastar ideas con profesionales de otros campos del conocimiento, de manera que se pueden compartir intereses con un restaurador de la entidad de Quique Dacosta o con las sugerentes propuestas de diseñadores, arquitectos e ingenieros como Miguel Fernández (FabLab), Mario de Alonso (Océano Naranja), José Ramón Tramoyeres (GGlab), o el colectivo Cul de Sac.

He considerado oportuno plantear mi análisis sobre las retóricas de la vajilla en base a tres aspectos que interactúan y se complementan entre sí, a saber:

a. La pasión por el trabajo bien hecho. Una reflexión sobre el papel del artesano en la era de la comunicación, a partir de los textos del filósofo y sociólogo pragmatista Richard Sennett. 
b. El acto de comunicar y la jerarquía de la mesa. Orientándome en los consejos y las lecturas de autores como Germán Navarro Espinach o Juan Vicente García Marsilla.

c. El acercamiento entre los discursos educativo y artístico desde la cultura visual. Con el fin de preparar a los diferentes públicos en aquellos aspectos estéticos y sociales que intervienen tanto en la cocina como en los nuevos hábitos alimentarios.

En la redacción del presente texto se intercalan inevitablemente cuestiones de orden autobiográfico, ya que es grande la motivación de orden personal por las temáticas que se tratan, teniendo en cuenta también que en mi planteamiento como investigador suelo abordar las cuestiones desde un modelo cualitativo (HUERTA, 2004), un esquema en el cual encajan aspectos como las historias de vida o las referencias de calado identitario (HUERTA, 2013). Por tanto, mi aportación está muy impregnada de constructos educativos, artísticos, motivacionales e incluso éticos.

\section{a. La pasión por el trabajo bien hecho}

En su libro El artesano, Richard Sennett considera que la "artesanía" es algo más que un modo de vida que languideció con el advenimiento de la sociedad industrial. Para Sennett "artesanía" significa en realidad un impulso humano duradero y básico: "el deseo de realizar bien una tarea, sin más" (SENNETT, 2013, p. 20). El propio autor sostiene que el buen artesano, además, emplea soluciones para desvelar un territorio nuevo, de modo que en la mente del artesano la solución y el descubrimiento de problemas están íntimamente relacionados. Si bien nuestro autor es reacio a utilizar en su libro la palabra creatividad, lo cierto es que su descripción anterior nos remite a un esquema vinculado directamente al terreno creativo e innovador: las personas creativas no solamente solucionan problemas, sino que cuestionan y resuelven las formas de plantear dichas problemáticas. Investigar y replantear son aspectos íntimamente unidos, ya que tan importante será solventar un problema como revisar el modo de abordarlo. Podemos considerar "artesano" al fabricante de botijos tradicionales, del mismo modo que puede definirse como artesano al usuario de Linux que gestiona este software libre. La artesanía es por tanto un posicionamiento, y la persona que se considera artesano establece una relación activa y dinámica con sus posibilidades y con sus intervenciones. 
En tal sentido, Sennett entiende que el saber artesanal "tiene como fundamentos tres habilidades básicas: la de localizar, la de indagar y la de desvelar. La primera implica dar concreción a una materia; la segunda reflexionar sobre sus cualidades, la tercera, ampliar su significado" (SENNETT, 2013, p. 340).

Lo dicho hasta aquí apunta hacia mi falta de prejuicios a la hora de utilizar el término "artesano", ya que lo entiendo como sinónimo de persona que intenta hacer bien las cosas, para lo cual arriesga y se supera. Yo provengo de una generación que todavía rebuscaba entre los despojos de la diferenciación entre "arte" y "artesanía”, una dicotomía ya superada. Nos tocó vivir el final de la modernidad y las últimas décadas del siglo XX intentando desubicar ciertos posicionamientos a todas luces caducos. Umberto Eco ironizaba sobre estas diferencias y contrastes absurdos desde su retórica de la semiocidad, en su libro que causó polémica titulado Apocalípticos e integrados (ECO, 1985), donde se criticaban las posturas enfrentadas entre quienes veían en la cultura de masas un signo de decadencia (los apocalípticos) o quienes lo encontraban tan deslumbrante que estaban dispuestos a dejar todo en manos de los medios (los integrados). A estas alturas del siglo XXI, cuando llevamos incorporadas de manera cotidiana tecnologías sofisticadísimas que nos permiten generar imágenes y compartirlas al instante con cualquier persona del mundo, en cualquier ubicación geográfica posible, seguir defendiendo criterios segregacionistas respecto a la cultura o a los procesos creativos resulta tan suicida como negar las evidencias de los cambios que se vienen produciendo tanto entre los públicos como entre las instituciones o los usos de cada objeto. Sin embargo, cabe indicar que desde las instituciones académicas sigue habiendo una diferenciación entre los estudios que capacitan para graduarse como "artista" o como "diseñador". En el caso de España, la titulación de Bellas Artes forma parte del entramado universitario, permitiendo obtener un título de grado, mientras que los estudios de diseño constituyen una tipología denominada "Estudios Superiores de Arte y Diseño" ajena todavía a las dinámicas universitarias. Puntualizo esta cuestión para clarificar que, si bien muchos profesionales no somos partidarios de dicha separación, lo cierto es que las dicotomías existen todavía a nivel curricular.

Entendemos que la obsesión por las imágenes tecnológicas que se verifica en el momento actual se puede comparar con la eclosión de imaginería que caracterizó el periodo final de la 
época medieval (ECO et alt., 1977). Resulta difícil incorporar imágenes que sean pregnantes en un espacio tan sofisticadamente abrupto como es el de la maraña icónica actual, y sin embargo los organizadores de estas jornadas han producido un material visual sugerente con el que han dado imagen al evento:

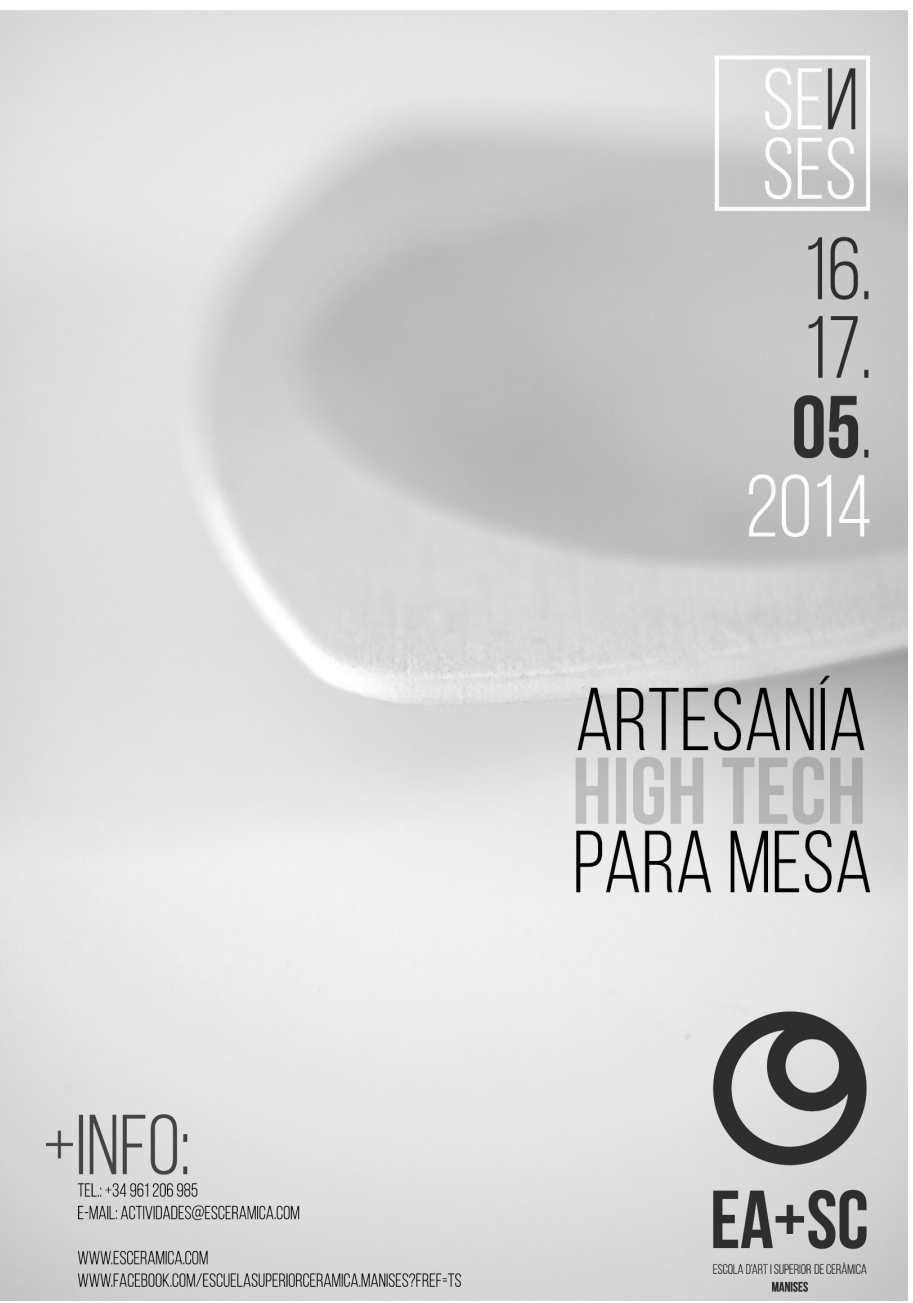

En el cartel que forma parte de la identidad visual de esta iniciativa Senses detectamos una combinación de texto e imagen que relata una intención de ofrecer, de manera sutil, un verdadero cambio estructural. Con esta iniciativa los organizadores quieren dejar constancia de que está tomando forma un modelo proyectual y creativo para el diseño de la vajilla. 
Por una parte están los nuevos usos de la cocina y las prácticas de los cocineros, que se han convertido en verdaderos gurús de la creación actual, una tradición contemporánea en la cual se alinean desde cocineros investigadores como Ferran Adrià hasta artistas multidisciplinares como Antoni Miralda. Por otro lado estaría el modelo de producción basado en la tecnología de impresión 3D. Ante el impacto de ambas realidades transformadoras, la EASC de Manises incorpora a su oferta una opción mediante la cual se investiga y se difunde este nuevo panorama de la creación culinaria. Para ello se utiliza en el afiche una tipografía de finísimo trazo, en tanto que la imagen que acompaña al texto se convierte en una especie de bruma en la que detectamos que asoma la arista roma de lo que entendemos que es un plato de cerámica de diseño actual. El cartel es limpio y contiene todos los datos que necesitamos. Pero además es sutil. Incluso pudiese parecer un guiño a uno de los platos más conocidos del cocinero Quique Dacosta: su bruma. Lo cierto es que el cartel se convierte aquí en puerta que se abre hacia una generosa propuesta de innovación.

Ricard Giralt Miracle, uno de los diseñadores clave del panorama español del siglo XX (HUERTA, 1994) decía, refiriéndose a las tipografías, que en la invención de letras y alfabetos, cuando hay una novedad realmente revolucionaria su llegada no se nota, sino que pasa casi desapercibida. Es después de un tiempo cuando se toma conciencia y se valora el cambio introducido. Afirmaba que las grandes tipografías se habían instalado de manera sutil, sin levantar polvaredas ni causar bajas. Giralt Miracle era un maestro, un artesano, un diseñador, un tipógrafo que estaba muy interesado en hacer las cosas bien. El sutil cartel de Senses me ha evocado el recuerdo de Giralt Miracle, así como su idea de que los grandes cambios no tienen necesariamente que ir acompañados de procesos violentos. Se escenifica un planteamiento del comer y de la presentación en la mesa de la comida que tiene que ver con los nuevos formatos que acompañan a las necesidades transformadas. Los cocineros quieren contar con una vajilla personalizada para sus particulares propuestas. Quienes vamos al restaurante queremos, más allá de lo que supone alimentarnos, vivir una experiencia placentera y sorprendente, incluso sofisticada. El deseo es aquí la piedra de toque. La necesidad ya no es únicamente comer, sino convertir la ingesta y su entorno en un proceso de experimentación, mediante el cual saborear nuevas experiencias. La vajilla forma parte de dicho ritual, y quienes piensan y realizan las nuevas va- 
jillas son, precisamente para esta ocasión, los profesores y el alumnado que comparten estímulos en esta Escuela de Cerámica de Manises. Esos nuevos formatos incluyen: la mirada, el tacto, el proceso creativo, la experiencia, la transmisión, la tecnología, y evidentemente, el deseo de hacer bien las cosas. Diseñar una vajilla en el momento actual supone valorar los diferentes factores que afectan al propio acto de comer como experiencia, ya que la parte visual del ritual resulta fundamental, además de tener en cuenta que las necesidades de todo tipo también son nuevas: quien cocina desea disponer de utensilios que permitan el uso de tecnologías innovadoras y que resulten prácticos a la hora de apilar o limpiar; quien degusta espera que le ofrezcan platos estéticamente atractivos y que estén dotados de un mínimo de sorpresa que, al mismo tiempo, favorezca una ingesta exquisita; quienes diseñan y fabrican estarán muy pendientes de los materiales y del precio del producto. Así pues, hay que tener en cuenta numerosos factores con el fin de innovar y satisfacer las necesidades actuales del ritual de la comida, algo que pueden abordar con éxito quienes desean hacer bien las cosas.

"El artesano representa la condición específicamente humana del compromiso" (SENNETT, 2013, p. 32). El compromiso es algo que lleva implícito el hecho de crear, pero también la profesión de educar. Sennett compara el oficio y su vertiente laboriosa con la paternidad:

No pensamos en el cuidado y educación de los hijos, por ejemplo, como oficio en el mismo sentido en que pensamos como oficio la fontanería o la programación, aun cuando para ser un buen padre o una buena madre hace falta un alto grado de destrezas aprendidas (SENNETT, 2013, p. 36).

Y ciertamente es necesario adquirir fortaleza en lo aprendido para poder transmitir con eficacia. El compromiso está siempre presente, si queremos hacer bien las cosas. Nos debemos comprometer, como creadores, y como profesores, como padres, e incluso como usuarios (comensales, clientes, visitantes, ciudadanos). Henry Giroux nos anima a concienciarnos de nuestro papel como intelectuales cuando ejercemos como profesores, indicándonos que "la pedagogía es una práctica moral y política que siempre se halla implícita en las relaciones de poder porque ofrece versiones y visiones particulares de la vida cívica, la comunidad, el futuro, y el modo en que podríamos construir representaciones de nosotros mismos, de los otros, y 
de nuestro medioambiente físico y social" (GIROUX, 2013, p. 15). Será el logro de calidad, el hacer un buen trabajo, la marca de identidad primordial del artesano, tanto si se trata de un ceramista profesional, de un profesor de cerámica, de un docente de cualquier disciplina y de cualquier nivel, como de un padre. La ciudadanía comprometida es algo que conviene transmitir. Lanzamos un mensaje de confianza hacia la docencia comprometida, animando a docentes y alumnado a compartir ese deseo de superación así como la confianza necesaria para aprender y el estímulo investigador para transmitir.

\section{b. El acto de comunicar en la jerarquía de la mesa}

Venimos reivindicando el placer por las cosas bien hechas, la transmisión de saberes y valores entre maestros y aprendices, el compromiso tanto personal como social, y desde luego la innovación y la investigación que pueden verificarse en las diversas formas de creatividad y en el ejercicio de la docencia. Como profesional de la docencia confío en las posibilidades de mi alumnado, y creo que un apartado importante para elaborar nuestro discurso docente es el de la motivación. Pertenecemos a generaciones distintas a las de nuestro alumnado, pero debemos mantenemos cercanos a sus intereses y deseos, observando cómo gestionan sus ubicaciones estéticas y sociales, o admitiendo que habita un entorno muy diferente al que fue el nuestro cuando éramos estudiantes. Podemos motivarles desde la confianza en sus posibilidades. Parafraseando a Sennett (2013, p. 134) "en la artesanía son necesarias la modestia y la conciencia de nuestras propias insuficiencias". Hacer las cosas bien no es una opción a escoger si no nos aporta conocimiento sobre nosotros mismos. Somos, en buena parte, lo que fueron nuestros antecesores. Vamos aprendiendo a ser en base a cada mínima inmersión en la realidad, y nos construimos gracias a la acumulación de pequeñas y numerosas prospecciones. Observamos las cosas gracias en parte a la mirada de nuestro alumnado. Y en este devenir de intercambios consolidamos los resultados. Desde el arte hasta la comida, desde la docencia hasta la motivación, todos los ámbitos del saber mueven nuestra curiosidad. Somos seres indagadores. La nutrición y la alimentación han servido para comunicar a lo largo de la historia. También las artes.

Empezamos a comer con la vista, y un plato nos resultará atractivo si está preparado de forma que al mirar nos resulte 
tentador. El mundo del arte ha tenido su particular historia con respecto a la nutrición, lo cual se ha evidenciado en un género tan aparentemente neutro como el de los bodegones, en los cuales se registran tanto alimentos como, especialmente, utensilios de comer, algo que podemos comprobar en pinturas como el Almuerzo (1914) de Juan Gris (MoMA, Nueva York), el Bodegón con cacharros (1650) de Francisco de Zurbarán (Museo del Prado, Madrid), o sobre todo en las escenas de la vida cotidiana, que de forma magistral supieron retratar los pintores holandeses del siglo XVII:, como en el caso del conocido lienzo La lechera (166o) de Vermeer (Rijkmuseum, Amsterdam). Si enlazamos esta tradición artística con las actuales producciones visuales, no resultará difícil comprobar hasta qué punto la imagen de la comida y los usos de la mesa están presentes tanto en el cine como en la publicidad, en la televisión y en el resto de medios, ya que todos tienen en los rituales del comer una parte importante de sus producciones. Pensemos en los anuncios de productos para comer y para cocinar. Los estudios de Roland Barthes (1986) supieron abordar de manera premonitoria estas cuestiones de lo cotidiano desde la vertiente semiótica.

Es en la estética de lo cotidiano donde se ubica nuestro interés primordial (MANDOKI, 2006). Cada día comemos entre dos y cinco veces. En cada una de esas ocasiones nos ubicamos en un ritual que incluye, además de los productos que ingerimos, todos aquellos objetos que tienen que ver con la conservación, el transporte y la seducción visual que puedan tener dichos productos. El hecho de comer constituye, a lo largo de nuestra vida, una de las actividades más constantes y fecundas. Sin embargo, y precisamente por su cotidianidad y reiteración, son pocas las veces que le dedicamos la atención que merece, como ritual y como acción creativa, a pesar de que sus repercusiones tanto fisiológicas como estéticas y/o espirituales. Las culturas orientales son mucho más respetuosas e incluso retóricas en dicho sentido, ya que las artes del comer constituyen fecundas expresiones de ritos con una trayectoria milenaria. Este edificante concepto de la comida se verifica y transmite en otras acciones cotidianas, como por ejemplo la escritura. Para nosotros escribir no supone mucho más que dejar constancia física de una serie de códigos comunicativos. Por el contrario, para las culturas milenarias orientales la escritura es sinónimo de arte. Ricard Giralt Miracle y Antoni Tàpies fueron admiradores de estas tradiciones orientales, especialmente de la japonesa; en el caso de Giralt con los Haikús y los 
Ikebanas, mientras que Tàpies se entusiasmaba con el ritual de la preparación del té. En ese sentido a mí me seduce particularmente la caligrafía china. Refiriéndose a dicha tradición, Herbert Read escribía:

los chinos normalmente escriben con un pincel y éste les resulta tan familiar como para nosotros pueda serlo un lápiz o una pluma. El primer hecho del que hay que darse cuenta en relación con la pintura china es que ésta es una ampliación de su escritura". (...) "Desde la pintura podemos pasar a las otras artes: escritura, cerámica, bronces, lacas, y en cada una de ellas encontraremos una calidad técnica similar, una sutilidad infinita en la que se refleja la personalidad del artista. En cerámica, por ejemplo, aparece en el contorno que forma el jarrón y en la relación de este contorno con el espesor y volumen de la pieza. Según la arcilla pasa por los dedos del alfarero sobre la rueda giratoria, expresa la sensibilidad de aquél con tanta seguridad y sutileza como el pincel cargado de tinta lo hace con la del pintor (READ, 1973, p. 96-97).

Los oficios establecen un criterio de tradición con las cosas bien hechas. Los oficios tienen la misma esencia creativa que el resto de las artes. La persona que crea tiene en sus manos una tradición milenaria a la cual debe reconocer su presencia. Avanzar significa, desde el respeto, escoger los mejores logros para encontrar nuevas preguntas. Del mismo modo que resultará complicado diseñar un buen alfabeto si no se conoce la tradición del diseño de letras, será complicado mejorar u optimizar el diseño de vajillas si no asumimos desde qué paradigma creativo nos planteamos el reto. Algo similar ocurre con el grabado, y es precisamente en la tradición de la estampa donde debemos reconocer el papel de Giorgio Morandi, quien nos ha dejado una obra repleta de connotaciones vinculadas a los enseres de la vajilla, tanto en sus pinturas (Naturaleza muerta, 1956, MAMBo, Bolonia) como en sus grabados (Naturaleza muerta, 1933, Collezione Estorick, Galleria d'Arte Maggiore di Bologna). A la parafernalia de los procesos de elaboración de la plancha de grabado y su estampación como obra seriada se le llama, curiosamente, "cocina del grabado". Un taller de grabado tiene destacadas similitudes con una cocina. El grabador utiliza los materiales para transformarlos, del mismo modo que el cocinero manipula los alimentos para convertirlos en platos atractivos y apetitosos. Hay algo de química y también un poco de alquimia en dichos procesos. La plancha es para el grabador 
algo así como la sartén para el cocinero. En el banco de grabado encontramos buriles, punta secas, bruñidores, rodillos, ceras, barnices, sal, azúcar, y un sinfín de artilugios que servirán para manipular la superficie de la matriz, del mismo modo que en el banco del cocinero hallamos sal, pimienta, cucharas, cuchillos, especias, verduras, carnes, aceite o huevos. La cola de conejo o la cola de pez han servido indistintamente durante siglos tanto a grabadores como a cocineros en sus talleres y cocinas. El gusto por encontrar una calidad apropiada, una textura diferente, o un contraste de apariencias, son retos que se plantea grabador al trabajar en el taller, del mismo modo que un cocinero investiga en los nuevos resultados que pueden dar sus creaciones. Resulta beneficioso dejarse llevar por las posibilidades de los materiales y tantear de ese modo nuevas opciones creativas, ya que la indagación conlleva riesgos y logros, y un investigador, tanto si le llamamos artista, grabador, cocinero o diseñador, debe entusiasmarse con este tipo de retos.

También la escultura impone relaciones con la cerámica o la vajilla en el arte más reciente. Claes Oldenburg utiliza para su obra escultórica referencias a objetos cotidianos, marcando así un nuevo ejemplo de uso de lo ordinario para convertirlo en extraordinario. En su pieza de 1961 titulada Pastry Case I, Oldenburg introduce esculturas de yeso pintadas sobre platos de cerámica, una fuente y varias tazas de metal, presentándolo todo en una vitrina de cristal y metal. Cuando Oldenburg creó esta pieza resultaba completamente innovador en el mundo del arte hacer uso de estos recursos, tanto estilísticos como de materiales. La ironía en la obra de Oldenburg afecta incluso a los orígenes desacralizantes de sus ideas, lo cual enlaza con el espíritu incorformista, y desde luego irónico de su predecesor Marcel Duchamp quien, por cierto, también nos legó una monstruosa taza de café (con su plato y su cucharilla) en la que se impone conceptual y visualmente una capa de piel de animal que la cubre.

Cocina y taller de grabado riman con diseño de vajilla e impresión 3D. Volvemos al maestro:

la categoría de artesano abarca más que la de artesano-artista; hombre o mujer, representa en cada uno de nosotros el deseo de hacer algo bien, concretamente y sin ninguna otra finalidad (SENNETT, 2013, p. 181).

Mirar al pasado "solamente puede tener una función de información cultural y se ha de considerar ligado a su tiempo", 
nos diría Bruno Munari (1985, p. 16). Pero no deja de tener su importancia revisitar el pasado, incluso adaptando sus logros a las necesidades actuales. Cada momento histórico ha vivido sus propias contradicciones, pero nuestra lectura será enriquecedora si sabemos aplicar la lección. No existe mucha diferencia entre la corrupción de políticos y banqueros que denunció George Grosz en sus dibujos y pinturas realizados en el Berlín de entreguerras, si la comparamos con la corrupción que podemos observar hoy en día entre nuestra clase política o empresarial. Lo importante, en última instancia, son los trabajos de Grosz.

La cerámica que se ha elaborado a lo largo de la historia es una fuente inagotable de inspiración. Se debe contrastar dicha tradición con las preguntas y las respuestas más actuales. La tradición cerámica valenciana es casi milenaria, y durante siglos se han fabricado piezas y conjuntos de cerámica en enclaves como Manises, Paterna o Alcora. Conocer este entramado histórico permite elaborar un saber que se nos ha transmitido en la forma de vivir y pensar. Si la fabricación de objetos de cerámica que conforman la vajilla bebe en nuestra geografía cercana de una tradición de siglos, también los usos y costumbres que se verifican en la cocina provienen de una tradición histórica que nos remite a la época medieval.

Comer es una necesidad individual que solemos satisfacer colectivamente. Las familias y los colectivos de todos los estratos sociales se reúnen en la mesa para compartir la comida. Ya en la época medieval la composición y el material de la vajilla dependía del rango del titular, y si bien campesinos y asalariados urbanos comían en platos de madera o de cerámica basta, lo señores utilizaban recipientes de estaño o de cerámica fina. Por tanto, también la comida ratifica la distribución por clases sociales con sus peculiaridades y características identificadoras. Además, la Iglesia, como portavoz de la ideología de las élites, define algunos rasgos básicos, como puedan ser los ayunos, las épocas de prohibición para ciertos alimentos, o incluso qué debían comer nobles y plebeyos, una diferencia que no se podía alterar. Un detalle: como la religión cristiana es heredera de la cultura greco latina, sus símbolos alimentarios como el pan, el vino y el aceite son, en realidad, reflejo de las bases materiales del Imperio Romano, sacralizadas en la liturgia. Como nos dice García Marsilla (1993, p. 68) "religión y ciencia se dan la mano y los intereses de ambas por regular los hábitos alimenticios de la sociedad se complementan". El mismo autor destaca que las ciudades son los escenarios fundamen- 
tales de este proceso. En ellas viven y se forman los médicos, que proceden en su mayoría de familias burguesas y utilizan su ciencia para ascender socialmente. En sus escritos, personajes medievales valencianos nos han dejado constancia del control de hábitos alimentarios que afectaban a la población, como es el caso del médico Arnau de Vilanova (con su Regiment de Sanitat), o de los clérigos Sant Vicent Ferrer (con sus Sermons) y Francesc Eiximenis (con su Terç del Crestià). Los argumentos religiosos apuntaban habitualmente al pecado de la gula, que llevaba aparejado el de la lujuria, siendo el comer en exceso un verdadero caldo de cultivo para la sodomía. La distinción, tal y como la definiese Pierre Bourdieu (2012), ya resultaba evidente en los rituales de la mesa de la época medieval.

En las ciudades bajomedievales la clase dominante, el patriciado urbano, debía convivir de forma mucho más directa con el resto de la sociedad que la nobleza altomedieval, cuya residencia en el castillo marcaba claramente su supremacía. Por eso a estaélitele interesaba remarcar la exclusividad desus privilegios en aquellos aspectos más cotidianos y visibles de su vida (MARSILLA, 1993, p. 77).

La cocina es un hecho cultural al tiempo que forma parte de las fuerzas productivas con las que modificamos nuestro entorno. Mediante las técnicas culinarias adaptamos los nutrientes naturales al gusto y a las posibilidades alimentarias, tal y como se apunta desde la antropología. Las mujeres han copado el entorno doméstico familiar de la alimentación, pero ya desde la Edad Media algunos hombres formaban parte como cocineros del servicio de los grandes señores. Este hecho, junto con la existencia de manuales de gastronomía (Llibre de Sent Soví, Llibre de Coch), confirma que en una época de gran efervescencia social como es la medieval, la existencia de una cocina aristocrática muy diferente de la popular contribuyó a transformar las costumbres cotidianas de la sociedad occidental. La cocina aristocrática, ejecutada por profesionales con unos utensilios muy especializados y que dedicaban todo su tiempo a esta actividad se caracterizaba, como hoy, por las recetas más elaboradas y difíciles, que resaltaban la habilidad del cocinero. Según García Marsilla (1993, p. 156)

se distinguían en aquella época dos tipos de platos según su confección y la forma de presentarlos en la mesa: las pietances y las cuines. Las primeras eran recetas de consistencia sólida, 
a base de carne o pescado, que se servían en platos planos o talladors, mientras que las cuines eran de consistencia más untosa o líquida y se servían en platos hondos o escudelles.

Lo cierto es que la cocina aristocrática siempre fue una realidad en constante cambio, ya que la búsqueda de nuevos manjares forma parte de las prácticas de ostentación que son inherentes a las capas altas de la sociedad (BOURDIEU, 2012). Por el contrario, la cocina popular mantiene sus constantes a largo plazo. Los ingredientes y la posibilidad de conseguirlos constituyen otro factor de distinción. A finales de la Edad Media la mayor variedad de especias indicaba un más alto rango social, mientras que la pimienta y el ajo, así como otros condimentos fáciles de conseguir se convirtieron en alimentos rústicos. Otra cuestión estética a tener en cuenta en el aspecto de los platos es el color que toman al ser preparados y la identificación que se produce en ocasiones entre un determinado color y un sabor, esto forma parte de la escenografía del banquete, ya que el factor visual siempre fue importante.

A finales de la Edad Media la cerámica de lujo de Manises y de Paterna era considerada un ornamento digno de las mesas más opulentas (López Elum 1984). La compañía Datini compró en 1401 doscientas cincuenta y seis piezas de cerámica del alfarero de Manises Azmet Zuleina para reexportarlas posteriormente a Venecia; entre ellas, aparte de los típicos platos planos y hondos aparecen también platos más pequeños, vasos, bacines, vasos con dos asas, salseras y alfabeguers - pequeños tarros
Figura 2

Plato de cerámica de

Manises del siglo XV

Figura 3

Plato de cerámica de Manises del siglo $X V$
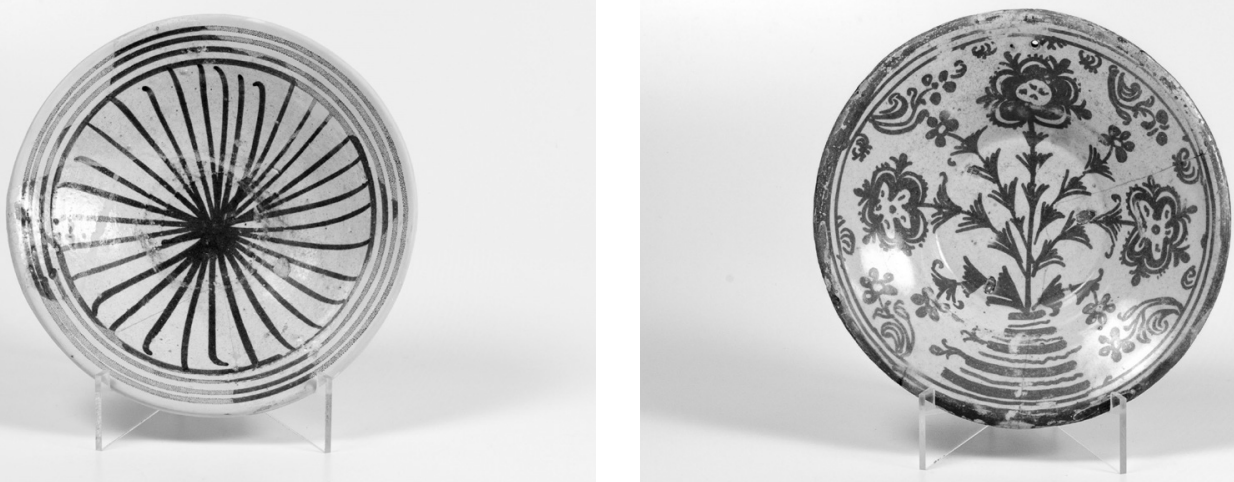
para conservar las hojas de albahaca -, todo un repertorio mucho más especializado en sus funciones, como corresponde a unas costumbres muy refinadas en la mesa (MARSILLA, 1993, p. 177). El entramado manufacturero e industrial que caracterizó a Valencia durante siglos coincide con la gran expansión comercial que vivió la ciudad desde el siglo XIV, lo que la convirtió en uno de los puertos clave del Mediterráneo occidental.

El resurgimiento de las ciudades en la Edad Media supone la aparición de grandes núcleos donde se agrupaban personas especializadas en el comercio o la industria, lo cual provocó un crecimiento de la economía europea con la implantación del feudalismo. La demanda de más productos y de mayor calidad estimuló esta división del trabajo. Curiosamente, la ciudad se endeudaba generando los llamados censales, que compraban los propios mercaderes. Pero aparte del efecto pernicioso de un endeudamiento crónico, "la venta masiva de censales por parte del municipio supuso que cada vez más capitales se desviaron a otras actividades más productivas, convirtiéndose Valencia en una ciudad de rentistas que vivían, paradójicamente, de los préstamos que la ciudad pedía para alimentarles" (MARSILLA, 1993, p. 280).

\section{c. El acercamiento entre los discursos educativo y artístico}

Recuperamos un texto de Roland Barthes de sus Mythologies, volumen recopilatorio de artículos que el autor publicó entre 1954 y 1956 y que fueron posteriormente editados en forma de libro. Con sus Mythologies Roland Barthes (1957) pretendía determinar dos cuestiones: por un lado elaborar desde el lenguaje una crítica ideológica de la cultura llamada de masas; por otra parte desmontar semiológicamente dicho lenguaje. Barthes había leído a Saussure y tenía la convicción de que tratando las "representaciones colectivas" como sistemas de signos se podía estudiar en detalle la mistificación que transforma la cultura burguesa en naturaleza universal. Esta ingenua, y sin embargo perspicaz, hazaña barthesiana nos ha hecho herederos de todo un complejo entramado de recursos para abordar los usos culturales. Barthes introduce en sus reflexiones de forma descarada los elementos de la cotidianidad: un anuncio de salsa para pasta, el diseño del Citroën DS, un programa de 
televisión,... Pero además emplea en su análisis semiológico referencias que incluyen aspectos de la sociología, la antropología, la estética, la política y, evidentemente, la retórica y la lingüística. Con estos antecedentes, Barthes se estaba anticipando a muchos de los argumentos de la posmodernidad, y podemos decir que se trata de un predecesor de lo que ahora llamamos las pedagogías culturales. El estudio de la cotidianidad supone elaborar argumentos sofisticados y amplios para analizar todo aquello que nos resulta cercano y que, en última instancia, es lo que realmente nos interesa. La ropa con que nos vestimos, las pantallas en las que indagamos, los transportes públicos con los que nos desplazamos, las tipografías que inundan la ciudad y que vemos a diario en nuestros paseos urbanos. A muchos de estos elementos les damos el nombre de "artefactos visuales" cuando los analizamos desde el paradigma de la cultura visual. Esta es la filosofía de investigación con la que argumento mis indagaciones. Esta es la perspectiva con la que se ha abordado el presente trabajo sobre las retóricas de la vajilla.

De las mitologías de Roland Barthes (1957) elegimos el texto que lleva por título "Cuisine ornementale" donde el autor recurre a las fotografías de platos cocinados que aparecen en la revista Elle ("véritable trésor mythologique" según Barthes). Se congratula de la sofisticación de los nombres que tienen las fotografías:

perdreaux dorés piqués de cerises, chaud-froid de poulet rosâtre, timbal d'écrevisses ceinturés de carapaces rouges, charlotte crémeuse enjolivée de dessins de fruits confits, génoises multicolores, etc.

Según Barthes, en este modelo de cocina, la categoría sustancial que domina es aquello que corona o cubre el plato ("le nappé"), con lo cual queda claro que lo que realmente interesa a quienes preparan este tipo de platos es la parte visual del acabado: "Cela tient évidemment à la finalité même du nappé, qui est d'ordre visual, et la cuisine d'Elle est une pure cuisine de la vue, qui est un sens distingué" (BARTHES, 1957, p. 128). De nuevo la distinción, el elemento diferenciador del que nos hablaba Pierre Bourdieu, otro autor que también argumentó desde (o frente a) los posicionamientos sociales de la burguesía francesa (y la de todo el planeta). Lo ratifica de nuevo Barthes: "Il y a en effet dans cette constance du glacis une exigence de distinction". Para 


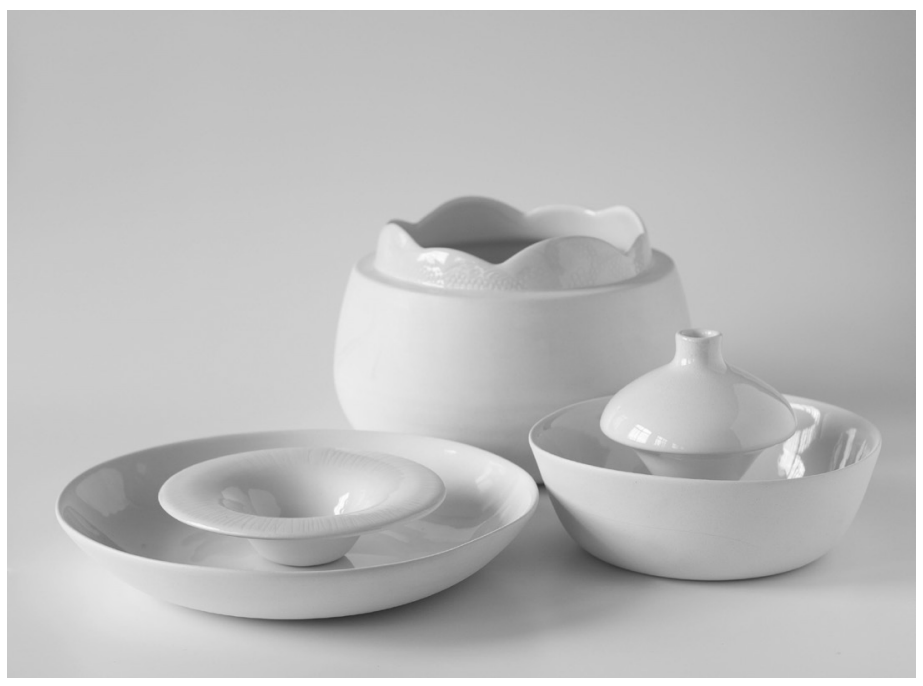

Barthes lo más inquietante de la cuestión es que el público de la revista Elle es la gente de las clases populares, personas que sueñan con un modelo de cocina más chic: "d’où une cuisine du revêtement et de l'alibi, qui s'efforce toujous d'atténuer ou même de travestir la nature première des aliments, la brutalité des viandes ou l'abrupt des crustacés". Se trata de generar coartadas para alejar la crudeza de la realidad, mediante la distinción. A partir de aquí la palabra clave: ornamentación. Los ornamentos serán, en definitiva, la reparación dialéctica de este comportamiento contradictorio: se ornamenta para trascender, y al mismo tiempo para ocultar, pero no se profundiza, sino que se sofistica en la ornamentación, es decir, en el envoltorio.

Según Barthes, esta cocina ornamental que presentan las revistas chic (y que devoran como publicaciones las clases populares) establece en última instancia una economía "mítica". Se trata de una cocina de ensueño, que es lo que pretenden las fotografías de Elle, presentando cada plato de manera que es al mismo tiempo un objeto próximo e inaccesible, ya que el consumo lo establece precisamente la mirada. Es, en un sentido pleno, una cocina de cartel, de anuncio, totalmente mágica, pero solamente posible para las clases sociales que económicamente podrían costearla y convertirla en platos reales, en comida, en sustancia comestible. Frente a los excesos de la mirada y de la distinción más frívola (aunque real) que nos relata Barthes, reflexionamos sobre las retóricas de la vajilla en su espectro nutricional, y para ello podemos utilizar obras 
de arte barroco que hablan de comida diseccionando algunos aspectos de la mirada que acompaña a la ingesta, como puede ser la pintura de Vincenzo Campi Vendedora de frutas (1580) de la Pinacoteca de Brera en Milán. Resaltemos de la obra de Campi su atrevimiento. Nos habla de una vendedora, de una persona anónima, de una comerciante de frutas. Pero nos cuenta al personaje desde un posicionamiento casi mitológico, ya que está rodeada de manjares, en este caso de frutas, un manjar codiciado en las mesas más refinadas de las ciudades.

A diferencia de la facilidad con que encontramos fruta en el medio rural, esta misma fruta se convierte en un bien preciado en las ciudades, con fecha de caducidad siempre precipitada. La vendedora de Campi nos ofrece un suculento y variado espectáculo de colores, texturas y formas, todas apetecibles, todas comestibles, todas sabrosas. El relato visual viene acompañado de muchas circunferencias, tanto entre las formas de las frutas como en los recipientes que las recogen. De dicho arsenal ovoide nos quedamos con las siete piezas de cerámica que mapean el lienzo (cuatro platos y tres cuencos o fuentes) que contienen higos, albaricoques y cerezas. Destacan en la pintura porque la mayoría son blancas, y esta exaltación del color blanco es posiblemente lo que macera su presencia. Frente a la exuberancia de la vendedora de frutas, otro modelo barroco mucho más introvertido, pero no por ello menos exultante sería el cuadro pintado por Francisco de Zurbarán titulado San Hugo en el refectorio.

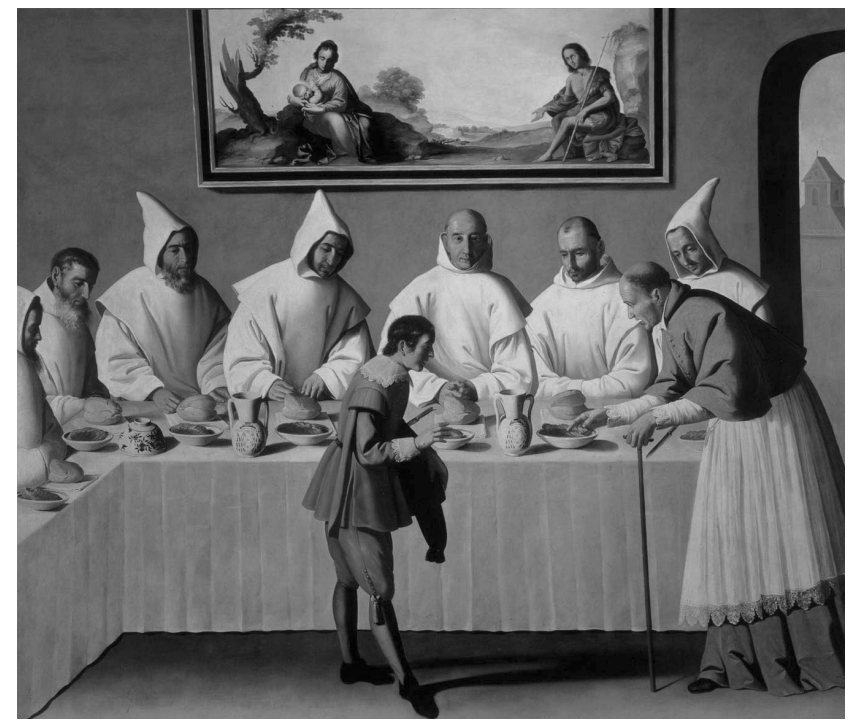

Figura 5

San Hugo en el refectorio de los cartujos (1655) Francisco de Zurbarán. Museo de Bellas Artes de Sevilla 
En esta obra destaca de nuevo la presencia de la cerámica. La cerámica fina fue durante siglos un objeto de lujo al que solamente podían acceder o los nobles o el estamento religioso, y posteriormente la burguesía. En el cuadro de Zurbarán recorremos con la mirada la parte central (el mantel blanco que cubre la mesa) donde observamos las piezas de cerámica que escalonan el recorrido de la mirada: siete platos hondos, dos vasijas y un cuenco. Se trata de cerámica de Talavera de la Reina, piezas decoradas, elementos clave de la composición, un conjunto en el que cada detalle ocupa su lugar y al que da la sensación que nos hemos de dirigir para entender su esencia, tanto individual como en relación al conjunto. De nuevo la mística como aderezo, pero en este caso no para ornamentar, sino para reclamar las esencias (la carne, el pan y el vino, el cuerpo y la sangre de Cristo en la mitología religiosa cristiana). San Hugo en el refectorio forma parte de una serie de lienzos que encargó a Zurbarán el prior de la Cartuja de Santa María de las Cuevas de Sevilla a mediados del siglo XVII. Al igual que en otras obras de Zurbarán, la vajilla adquiere el valor de esencia mística. Lo cotidiano, lo sencillo y lo desnudo como sistema simbólico. El lenguaje de la visión toma forma aquí a partir de los elementos cotidianos, dotándolos de entidad más allá de su mera presencia: dotándoles de alma (ERRÁZURIZ, 2006).

También en el ámbito educativo luchamos por mejorar los procesos. Para Senett (2013, p. 17) "el buen maestro imparte una explicación satisfactoria", mientras que "el gran maestro produce inquietud, transmite intranquilidad, invita a pensar". La fuerza de los docentes y el poder que ejercen en la formación de la ciudadanía supone un aliciente (HUBARD, 2008), pero se trata sobre todo de un reto y una responsabilidad para quienes nos encargamos de formar a los futuros maestros (AUGUSTOWSKY, 2012; FREEDMAN, 2008). Tesis doctorales como la de Ricard Ramon (2012) o la de Marc Ribera (2013) tantean de forma colaborativa las posibilidades de la vajilla y su presencia cultural en la sociedad y en la educación.

En relación con las teorías y prácticas que se están promoviendo desde la educación artística, la cultura visual (DUNCUM, 2008) o las pedagogías culturales sugieren mayor amplitud para abordar nuevas temáticas. También las artografías (a/r/tographies) difundidas por Rita Irwin (IRWIN \& O'DONOGHUE, 2012; IRWIN, 2013) defienden un modelo educativo en el que el profesorado asume su papel como artista, docente e investigador (de ahí las iniciales del acróstico a/r/t $=$ artist, teacher, researcher). Este modelo resulta beneficioso 
para el docente, ya que su formación como artista le permite establecer en el aula los parámetros en los que se formó: trabajo por proyectos, importancia del taller, manipulación de materiales, y sobre todo presencia y empoderamiento del espacio como elemento clave en la producción creativa. El profesorado que utilice las artografías como enfoque de trabajo colaborativo implicará al alumnado, tanto en lo tecnológico como en la transmisión de ideas. Por su parte, el modelo Arts Based Education (educación basada en las artes) propicia un acercamiento a las imágenes, contagiándolas de elementos que ya han sido refrendados por anteriores artistas. Se trata de generar investigación a partir de la creación de imágenes, y de que estas imágenes supongan por ellas mismas un resultado de la investigación.

En lo referido a la educación en patrimonio, recomendaros los avances del Observatorio de Educación Patrimonial en España (www.oepe.es), proyecto que dirige Olaia Fontal y que delimita nuevos espacios de actuación para la educación artística (FONTALy VALLÉS, 2013; HUERTA y CALLE, 2013), utilizando como referente el potencial de los patrimonios. Por lo que respecta al entorno de reflexión y acción de la cultura visual (DUNCUM, 2007), conviene aclarar que se trata de un planteamiento docente e investigador donde los artefactos visuales son analizados en base a cuestiones de orden visual, pero siempre contextualizados en su entorno cultural y político, optando por elaborar discursos a partir de los intereses de los usuarios. Si tomamos como ejemplo el plato de la figura 6, una pieza del artista Xavier Montsalvatje, domina el color azul y las figuras reconocibles, si bien el trabajo de Montsalvatje tiene una intención absolutamente implicada con su realidad. Se expresa mediante una técnica que va más allá de la opción por elaborar un recipiente para comer. Utiliza un medio de expresión, que en este caso es el plato de cerámica, y por tanto un elemento con un bagaje histórico particular. Pero el artista lo recrea introduciendo sus particulares intereses estéticos y creativos, dotándolo de poder reivindicativo con resonancias políticas y culturales. Esta lectura poliédrica es la que favorece la cultura visual, que está muy pendiente de los nuevos modelos de pedagogías culturales, con una real implicación social.

La posibilidad de utilizar en la docencia ejemplos de cualquier época, siempre que los adaptemos a nuestros intereses, nos recuerdan de nuevo las palabras de Sennett: "El taller del artesano es el escenario en el que se desarrolla el conflicto moderno, y tal vez irresoluble, entre autonomía y autoridad" (SENNETT, 2013, p. 104). La autoridad la gana el docente con su ejemplo, y la reafirma depositando confianza en su alumnado. 
Figura 6 Plato de cerámica (2013) de Xavier Montsalvatje

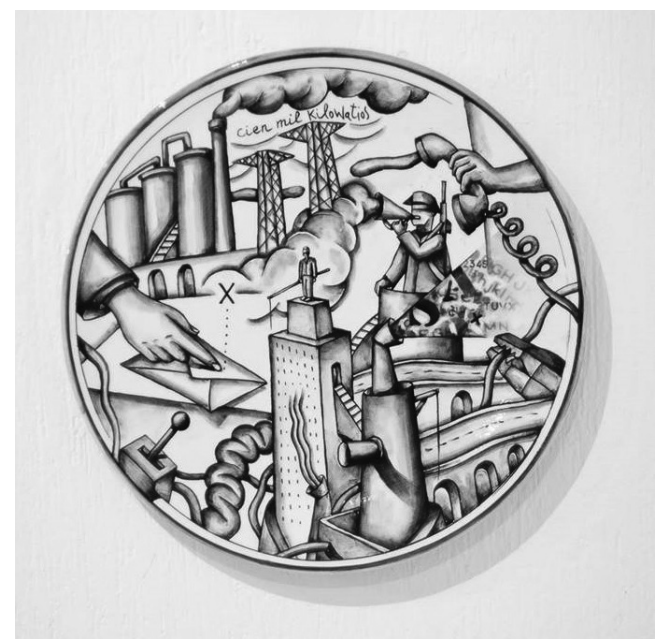

Mirando hacia las posibilidades futuras que nos depara la tecnología, incido en el trabajo del arquitecto José Ramón Tramoyeres, personaje clave del Green Geometries Laboratory GGlab (http://www.gglab.org/blog/aboutus), quien ha elaborado proyectos interesantísimos de cocina junto con el restaurador Paco Morales, utilizando elementos elaborados mediante impresión en $3 \mathrm{D}$, tanto en lo referido a creación de los recipientes como a la confección de los propios alimentos. Dibujar alimentos o recipientes para éstos y crearlos al mismo tiempo mediante tecnologías de impresión 3D supone transformar el proceso de gestación de los alimentos, construyendo así una nueva relación entre el creador (cocinero, diseñador) y el propio producto, lo cual nos lleva a establecer un novedoso parámetro de comunicación entre el creador y los usuarios. Esta impronta, que al mismo tiempo elimina y desestabiliza las tradicionales fronteras de la creación, supone para nosotros una adaptación ante la cual debemos posicionarnos, generando flujos relacionales e innovando en todos los sentidos. Hacer hoy una vajilla, diseñándola como producto, supone establecer curiosos contactos con los renovados usuarios. La capacidad para adaptarse a este original acontecimiento será la clave para iniciar nuevas empresas.

La tecnología $3 \mathrm{D}$ nos está deparando constantes sorpresas. Una de ellas es el lápiz LIX 3 D Printing Pen, que permite dibujar en el espacio construyendo líneas que se entrelazan para crear objetos tridimensionales. En lo referido a la imagen 3D, algunos museos están presentando ya sus proyectos de visitas virtuales en tres dimensiones. Precisamente el Museo Nacional de Artes Decorativas de Madrid está elaborando su 
proyecto dentro del programa europeo ArtSenses, siendo una de las iniciativas proveer al público de soportes en realidad aumentada para su conocimiento de una de las piezas clave del museo: la cocina valenciana (DAMALA, 2013).

\section{Conclusiones}

En una Escuela de Cerámica el artefacto visual por excelencia es la vajilla, ya que las narraciones de la mesa se nutren, básicamente, de los utensilios que acompañan al alimento propiamente dicho. Aquí se habla de platos, tazas, tazones, boles, cuencos, fruteros, jarras, jarrones, soperas, salseras, hueveras, y tantos objetos más que, además de resultar útiles e indispensables para cocinar y comer, se convierten en artefactos visuales de gran entidad, en los que están implicados factores de orden estético, artístico, social, personal, antropológico, político, industrial y comercial. Conviene no olvidar la riqueza de la tradición artesanal e industrial de cada territorio, y más teniendo en cuenta las proximidades geográficas (LÓPEZ ELUM y CONESA, 2006), respetando las relaciones que se establecen entre cotidianidad y usos culturales. Pero también hemos de plantearnos que en un centro de formación se barajan y se resuelven vivencias que incluyen, además, aspectos educativos y pedagógicos (AGUIRRE, 2004; CSIKSZENTMIHALYI, 1990), Aquí se habla de historia, de recursos, de técnicas y de proyectos. Resulta evidente que en el espíritu del profesorado anida la ilusión de generar una identidad propia (ROGOFF, 200o), de estimular intereses como creadores y como investigadores. El resultado de todas estas intenciones conducirá a lograr los diseños de vajillas que inundarán de apetitosas ideas las mesas de los futuros comensales, un esfuerzo que nos permitirá avanzar sosegadamente para conseguir un entorno más justo, más equitativo y más equilibrado.

\section{Referencias}

AGUIRRE, I. Beyond the Understanding of Visual Culture: A Pragmatist Approach to Aesthetic Education. International Journal of Art E Design Education, 23 (3), 256-269, 2004.

AUGUSTOWSKY, G. El arte en la enseñanza. Buenos Aires: Paidós, 2012.

BARTHES, R. Mythologies. Paris: Éditions du Seuil, 1957.

BARTHES, R. Lo obvio y lo obtuso. Barcelona: Paidós, 1986.

BOURDIEU, P. La distinción. Criterios y bases sociales del gusto. Barcelona: Taurus, 2012. 
CSIKSZENTMIHALYI, M. The Art of Seeing. An Interpretation of the Aesthetic Encounter. California: The J. Paul Getty Trust, 1990.

DAMALA, A. An Introduction to Augmented Reality and Cultural Heritage for Curators, Art Historians and Museum Educators. En Cabrera. A. et alt. (coord.) La cocina valenciana del Museo Nacional de Artes Decorativas. Una relectura a través de la tecnología de Realidad Aumentada. Madrid: Ministerio de Educación, Cultura y Deporte, 2013.

DUNCUM, P. Aesthetics, Popular Visual Culture, and Designer Capitalism, International Journal of Art $\mathcal{E}$ Design Education, 26 (3), 285-295, 2007.

DUNCUM, P. Holding Aesthetics and Ideology in Tension, Studies in Art Education, 49 (2), 122-135, 2008.

ECO, U. Apocalípticos e integrados. Barcelona: Tusquets, 1985.

ECO, U. et alt. La nueva edad media. Madrid: Alianza, 1977.

ERRÁZURIZ, L. H. Sensibilidad estética. Un desafío pendiente en la educación chilena. Santiago de Chile: PUC, 2006.

FONTAL, O. \& VALLÉS, J. Mucho más que... Ampliando horizontes para la educación patrimonial. En Huerta \& de la Calle (eds) Patrimonios migrantes. Valencia, PUV: 149-158, 2013.

FREEDMAN, K. Leading Creativity: Responding to Policy in Art Education. Eça, T. \& Mason, R. (eds.) International Dialogues about Visual Culture, Education and Art (pp. 3947). Bristol: Intellect, 2008.

GARCÍA MARSILLA, J. V. La jerarquía de la mesa. Los sistemas alimentarios en la Valencia bajomedieval. Valencia: Diputación de Valencia, 1993.

GIROUX, H. La pedagogía crítica en tiempos oscuros. Praxis Educativa, 17, 2, pp. 13-26, 2013.

HUBARD, O. The Act of Looking: Wolfgang Iser's Literary Theory and Meaning Making in the Visual Arts, International Journal of Art and Design Education, 27 (2), 168-180, 2008.

HUERTA, R. Funció plàstica de les lletres. Picanya: Bullent, 1994.

HUERTA, R. Cultura visual a Ontinyent. Ontinyent. Caixa Ontinyent, 2004.

HUERTA, R. La identidad como geografía liminar. Nuevas ideas para la educación en artes visuales. Aula de Innovación Educativa, 220, 11-17, 2013.

HUERTA, R. \& DE LA CALLE, R. (eds.) Patrimonios migrantes. Valencia: PUV, 2013.

IRWIN, R. Becoming A/r/tography. Studies in Art Education: A Journal of Issues and Research, 54 (3), 198-215, 2013.

IRWIN, R. \& O'DONOGHUE, D. Encountering Pedagogy 
trough Relational Art Practices. International Journal of Art E Design Education, 31 (3), 221-236, 2012.

LÓPEZ ELUM, P. Los orígenes de la cerámica de Manises y de Paterna (1285-1335). Valencia: Federico Doménech, 1984. . Los utensilios de cocina y mesa en la Baja Edad Media: los materiales empleados en su fabricación. Saitabi, 5152, pp. 101-112, 2001.

LÓPEZ ELUM, P. y COLL CONESA, J. La producción cerámica de lujo en la Baja Edad Media: Manises y Paterna. Los materiales de los recipientes para su uso alimentario: su evolución y cambios según los inventarios notariales. Valencia: Amigos del Museo Nacional de Cerámica, 2006.

MANDOKI, K. Estética cotidiana y juegos de la cultura. México: Siglo XXI, 2006.

MUNARI, B. Diseño y comunicación visual. Contribución a una metodología didáctica. Barcelona: Gustavo Gili, 1985.

RAMON, R. Lladró: análisis de la creación cultural de una estética. De la tradición industrial de la cerámica valenciana a la recepción social de una marca. Universitat de València. Tesis doctoral, 2012.

READ, H. El significado del arte. Madrid: Magisterio Español, 1973.

RIBERA, M. Activitats educatives dels museus de ceràmica valencians. Estratègies del professorat. Universitat de València. Tesis doctoral, 2013.

ROGOFF, I. Terra Infirma: Geography's Visual Culture. New York: Routledge, 2000.

SENNETT, R. El artesano. Barcelona: Anagrama, 2013.

Recebido em: 25/05/14

Aceito em: 29/07/14

\author{
RICARD HUERTA \\ ricard.huerta@uv.es \\ Ricard Huerta es profesor de educación artística en la Facultat de \\ Magisteri de la Universitat de València. Director del Instituto de \\ Creatividad e Innovaciones Educativas. Director de la revista EARI \\ Educación Artística Revista de Investigación y del Diploma de posgrado \\ Educación Artística y Gestión de Museos.
}

